\title{
Association Between In-hospital Supportive Visits by Primary Care Physicians and Patient Outcomes: A Population-Based Cohort Study
}

\author{
Stacey S. Brener, MSc1 , Susan E. Bronksill, PhD,2, Rebecca Comrie, MSc ${ }^{3}$, Anjie Huang, MSc1 , Chaim M. Bell, MD, PhD ${ }^{1,2,4 *}$
}

${ }^{1}$ Institute of Health Policy Management \& Evaluation, University of Toronto, Toronto, Canada; ${ }^{2}$ nnstitute for Clinical Evaluative Sciences, Toronto, Canada; ${ }^{3}$ Cancer Quality Council of Ontario, Toronto, Canada; ${ }^{4}$ Department of Medicine, University of Toronto and Mount Sinai Hospital, Toronto, Canada.

BACKGROUND: One long-standing method for continuity of care as patients transition between the hospital and community are supportive visits by primary care physicians during hospitalization.

METHODS: This retrospective cohort study used administrative data of adults hospitalized from 2008 to 2009 and primary care physicians who conduct supportive visits. Patients who received a visit from their primary care physician while hospitalized were compared to those who did not. Composite outcomes of death, emergency department visit, or emergent readmission within 30 and 90 days were assessed. Postdischarge home-care utilization and primary care physician visits were also examined. Multivariate logistic regression models adjusted for age, sex, low income, rurality, and readmission risk.

RESULTS: Of the 164,059 patients linked to 3236 primary care physicians, $12.0 \%$ received visits while hospitalized.
Visited patients had more readmissions, more deaths, and fewer emergency department visits than patients who did not. However, after adjusting, visited patients had a lower risk for the composite outcome at 30 days (adjusted OR [aOR]: 0.92; 95\% confidence interval [Cl]: 0.89-0.96) and 90 days (aOR: 0.90; 95\% Cl: 0.87-0.92). Visited patients were also more likely to access community primary care-provider visits and more home-care services. The in-hospital visit resulted in an increased likelihood of health services utilization at 30 days (aOR: 1.16; 95\% $\mathrm{Cl}: 1.11-1.22$ ) and 90 days (aOR: 1.20; 95\% Cl: 1.12-1.27).

CONCLUSION: A hospital supportive-care visit from a primary care physician resulted in lower risks of adverse patient outcomes and increased access to community health services. Journal of Hospital Medicine 2016;11:418424. (C) 2016 Society of Hospital Medicine
Transitions in care are vulnerable periods. As patients are transferred between settings of care (such as from hospital back to the community), communication between healthcare providers is vital for care continuity. ${ }^{1}$ A significant number of preventable adverse events may be related to ineffective communication between care providers. ${ }^{1-3}$ The advent of specialized care, such as the introduction of hospitalists in acute care settings, has created an environment in which a patient's most responsible physician can often change multiple times as they move through the healthcare system. ${ }^{4}$ Although there are many benefits to this type of concentrated care, the increase in care transitions may result in breakdowns in communication that may then be linked to risks in patient safety and suboptimal patient outcomes. ${ }^{5-8}$

Improved continuity of care has been demonstrated to enhance patient safety during care transitions. ${ }^{7}$

\footnotetext{
*Address for correspondence and reprint requests: Chaim Bell, MD, Mount Sinai Hospital, 600 University Avenue, Suite 433, Toronto, Ontario M5G 1X5, Canada; Telephone: 416-586-4800; Fax: 416-586-8864; E-mail: cbell@mtsinai.on.ca

Additional Supporting Information may be found in the online version of this article.

Received: June 2, 2015; Revised: January 20, 2016; Accepted: January 25, 2016

2016 Society of Hospital Medicine DOI 10.1002/jhm.2561

Published online in Wiley Online Library (Wileyonlinelibrary.com).
}

Efforts to develop continuity of care interventions are largely focused on care-provider continuity, improved facilitation of communication, care planning, and increasing involvement of primary care physicians during follow-up to hospitalizations and specialist visits. ${ }^{9,10}$ Such continuity of care efforts may provide a moderate benefit, but there remains room for improvement. ${ }^{10,11}$

One dimension of continuity of care that has received limited attention is the potential impact of primary care physicians hospital visits to their hospitalized patients in a supportive-care role. ${ }^{12}$ In these situations, the primary care physician is neither the most responsible physician nor are they involved directly in their patient's hospital care. However, visiting their patient implies that they are aware of the hospitalization, thereby facilitating the potential for communication between care providers. Primary care physicians can also provide valuable contextual and relevant information as well as be involved in the discharge process. To identify the extent to which primary care physicians visit hospitalized patients and to measure the potential impact of primary care physician supportive visits on future outcomes, we used population-level data to determine the frequency of supportive-care visits by primary care physicians to hospitalized patients and to identify the association between these visits, patient outcomes, and health services utilization. 


\section{METHODS}

\section{Overview}

We applied a retrospective cohort design utilizing linked population-based administrative databases in the province of Ontario, Canada to examine outcome differences between patients who received a supportive-care in-hospital visit by their primary care physician compared to those who did not.

\section{Databases}

We assembled the cohort from linked and encrypted population-based healthcare administrative databases. Data were derived from information on patients and physicians from the Ontario Health Insurance Plan, the Canadian Census, the Canadian Institute of Health Information Hospital Discharge Abstract Database, Registered Persons Databases, National Ambulatory Care Reporting System, Corporate Provider Database, Client Agency Program Enrolment, and Home Care Database. These databases have been validated and widely used in numerous studies. ${ }^{13-15}$ All adults aged $\geq 18$ years who were discharged from the hospital in Ontario, Canada between January 1, 2008 and December 31, 2009 were included. Patients transferred to nursing homes or other acute care facilities following discharge, including rehabilitation centers, were excluded because they may have different readmission patterns. Among remaining hospitalized patients, only those with an identifiable primary care physician in the community were included. The patient-primary care physician pairings were identified using validated algorithms based on historical physician billing information. ${ }^{16}$ This approach, adapted from previous studies, maximized the comparability among the study groups. ${ }^{17,18}$ In addition to having an historical relationship with the patients, primary care physicians had to have a history of conducting in-hospital supportive visits (i.e., visits to at least 2 hospital patients within the previous year) for the patient-primary care physician pair to be included. This criterion was included to increase the likelihood that we were capturing a usual physician practice behavior and not a single circumstantial visit by a primary care physician. The history of supportive visits was also identified with physician billing data using a specific fee code.

\section{Exposure}

The exposure of interest was an in-hospital visit in a supportive-care role by the primary care physician during a patient's hospitalization and was obtained from physician fee codes. The fee paid for a visit during the study period was less than \$20 CND.

\section{Outcome Measures}

Two different composite outcome measures were examined. The primary outcome was a composite of an emergent hospital readmission, death, or emergency department visit (without hospital admission). A com- posite measure was utilized to account for all outcomes simultaneously and thus be representative of the overall patient experience. ${ }^{19}$ This approach has been applied in several studies examining continuity of care. ${ }^{19-21}$ The secondary outcome examined processes of care. It was a composite evaluating ambulatory health services use postdischarge, specifically the number of primary care physician office visits and formal (ie, paid for by the universal provincial health plan) home-care services. Home-care services included both visits for nursing care as well as formal social support such as personal care. All outcome measures were assessed at 30 and 90 days following hospital discharge to assess for short and medium range outcomes. ${ }^{22}$

\section{Patient Characteristics}

Patient demographics including age, sex, low income (defined as individual income below \$16,018 [CND] or couples income below $\$ 24,175$ [CND]), living in a rural region, and the number of previous visits with primary care physicians were described from the available data. Readmission risk from the initial hospitalization was calculated based on the LACE score. ${ }^{23}$ The LACE score is a validated measure of 30-day readmission risk based on healthcare administrative data that account for (L) length of stay, (A) acute admission, (C) comorbid disease burden, and number of (E) emergency department visits in previous 6 months. ${ }^{23}$ The LACE score ranges from 0 to 19 , which correspond to a probability of readmissions of $2 \%$ to $43.7 \%$, respectively. We considered individuals to have a high risk of readmission with a LACE score $\geq 10$, which corresponds to a probability of readmission of $12.2 \% .^{23}$

\section{Statistical Analyses}

Descriptive statistics were used to compare patient characteristics among those with a primary care physician supportive-care visit to those without. Logistic regression modeling was conducted to examine the impact of primary care physician visits on outcomes. The results reported here reflect the selection of adjusting for the confounders of age, sex, a history of primary care physician visits, low income, rurality, and the LACE score.

\section{Ethics}

The project analysis was conducted at the Institute for Clinical Evaluative Sciences (ICES) in Toronto, Ontario and was approved by the Sunnybrook Health Sciences Centre Research Ethics Board.

\section{RESULTS \\ Overview}

There were 11,316 primary care physicians identified as practicing in Ontario during the study period, of which 3236 had a history of conducting regular inhospital visits to 2 or more patients. The final patient cohort consisted of 164,059 hospitalized patients; 


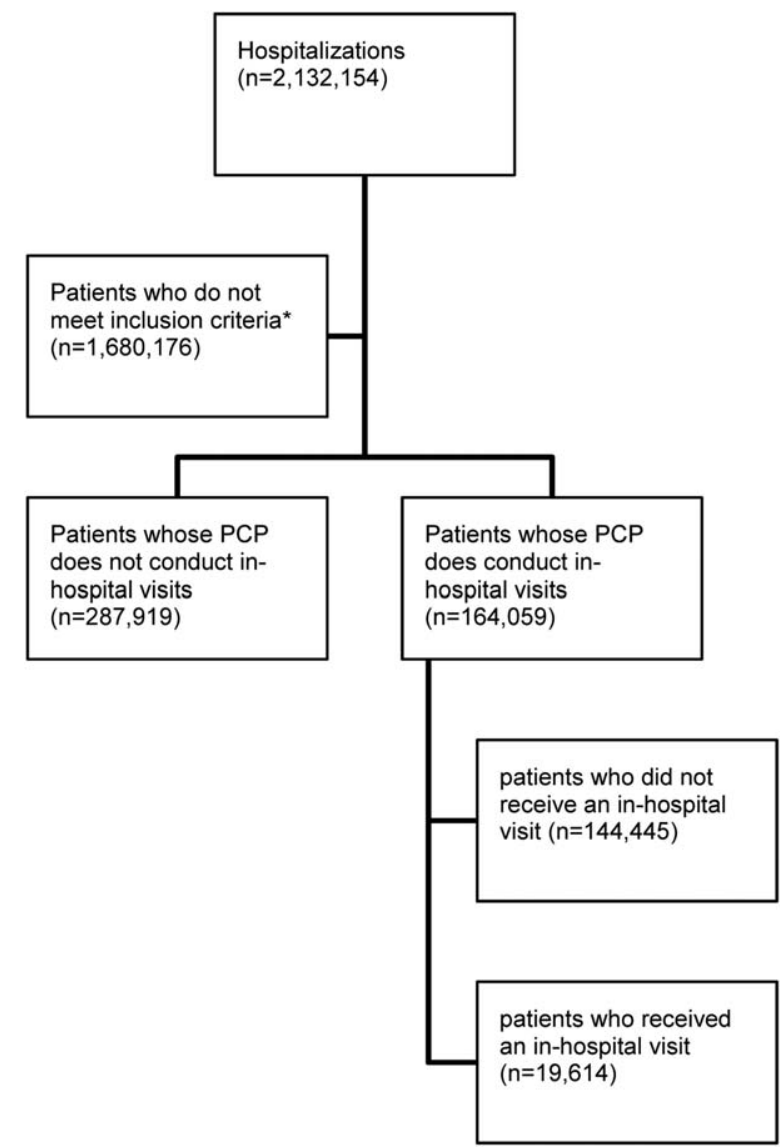

FIG. 1. Patient cohort development. *Patients were excluded if they were $<18$ years of age, died before or during index hospitalization, were nonmedical patients (eg, psychiatric or obstetrics), were discharged to an acute care facility (eg, transfer between hospitals), or were missing data or data were not otherwise available. Abbreviations: PCP, primary care physician.

19,614 patients received a visit from their primary care physician, whereas 144,445 did not (Figure 1).

The hospitalized patients who received a visit from their primary care physician were significantly different than the patients who did not receive an inhospital visit (Table 1). Notably, patients who received a visit by their primary care physician had longer lengths of hospital stay (9.7 days vs 6.8 days, $P<0.001)$. As well, a greater proportion had a high 30 -day readmission risk (LACE score $\geq 10: 39.4 \%$ vs $29.9 \%, P<0.001)$ (Table 1). ${ }^{21}$

Patients who received an in-hospital visit by their primary care physician were significantly different from those who did not (Table 2). They were older (68.4 years vs 65.7 years), and had a higher risk of readmission (LACE score of 9 vs 8 ). As well, proportionally fewer patients who received a visit were from rural regions than in the comparator group $19.9 \%$ of patients visited were from rural regions vs $17.8 \%$ of patients who did not receive a visit) (Table 2).

\section{Individual Outcomes}

Patients who received an in-hospital visit by their primary care physician were also more likely to be readmitted within 30 days of discharge $(8.9 \%$ vs $7.8 \%$,
TABLE 1. Patient Characteristics for the Cohort

\begin{tabular}{|c|c|c|}
\hline Variable $^{\star}$ & $\begin{array}{c}\text { With PCP } \\
\text { Visit } \\
(\mathrm{N}=19,614)\end{array}$ & $\begin{array}{c}\text { Without } \\
\text { PCP Visit } \\
(\mathrm{N}=144,445)\end{array}$ \\
\hline Age, mean $\pm S D$ & $68.37 \pm 16.85$ & $65.73 \pm 18.54$ \\
\hline Sex, no. of males & $9,393(47.9 \%)$ & $67,030(46.4 \%)$ \\
\hline Low income $\dagger$ & $3,937(20.1 \%)$ & $30,157(20.9 \%)$ \\
\hline Individuals living in rural regions, no. & $1,951(9.9 \%)$ & $25,731(17.8 \%)$ \\
\hline PCP visits in previous 6 months, mean \pm SD & $4.76 \pm 4.47$ & $4.17 \pm 4.28$ \\
\hline Length of stay, $d$, mean $\pm S D$ & $9.72 \pm 17.40$ & $6.79 \pm 13.17$ \\
\hline Acute emergent visits, no. & $19,138(97.6 \%)$ & $136,374(94.4 \%$ \\
\hline Charlson score, mean \pm SD & $1.06 \pm 1.60$ & $0.92 \pm 1.49$ \\
\hline ED visits in previous 6 months, mean $\pm S D$ & $0.95 \pm 1.48$ & $1.09 \pm 1.98$ \\
\hline LACE score, mean $\pm S D^{\ddagger}$ & $9.02 \pm 2.88$ & $8.10 \pm 3.02$ \\
\hline High risk for readmission (LACE score $\geq 10)$, no. $(\%)^{\ddagger}$ & $7,721(39.4 \%)$ & $43,126(29.9 \%)$ \\
\hline
\end{tabular}

NOTE: Abbreviations: ED, emergency department; PCP, primary care physician; SD, standard deviation. ${ }^{*}$ All results are statistically significantly different $(P<0.0001)$.

'Low income is defined as individual income below $\$ 16,018$ (CND) or couples income below $\$ 24,175$ (CND).

LACE score is a validated measure predicting readmission risk and accounts for length of stay, acute admission, comorbid disease burden, and number of ED visits in previous 6 months. The probability of readmissions range from $2 \%$ for a score of 0 to $43.7 \%$ for a LACE score of 19 ; LACE score of 10 corresponds to a probability of readmission of $12.2 \%{ }^{20}$

\begin{tabular}{|c|c|c|c|}
\hline Variable & $\begin{array}{l}\text { Received an } \\
\text { In-hospital Visit } \\
(\mathrm{N}=19,614)\end{array}$ & $\begin{array}{l}\text { Did Not Receive } \\
\text { an In-hospital } \\
\text { Visit }(\mathrm{N}=144,445)\end{array}$ & $P$ Value \\
\hline \multicolumn{4}{|c|}{$\begin{array}{l}\text { Primary outcome of emergency department visit, hospital readmission, or death } \\
30 \text { days postdischarge, no. }(\%)\end{array}$} \\
\hline Readmission & $1,742(8.9 \%)$ & $11,212(7.8 \%)$ & $<0.001$ \\
\hline ED visit & $2,039(10.4 \%)$ & $16,823(11.6 \%)$ & $<0.001$ \\
\hline Death & $727(3.7 \%)$ & $4,688(3.2 \%)$ & $<0.001$ \\
\hline Composite endpoint* & $4,227(21.6 \%)$ & $30,848(21.4 \%)$ & 0.533 \\
\hline \multicolumn{4}{|l|}{90 days postdischarge } \\
\hline Readmission & $2,791(14.2 \%)$ & $18,257(12.6 \%)$ & $<0.001$ \\
\hline ED visit & $3,652(18.6 \%)$ & $29,590(20.5 \%)$ & $<0.001$ \\
\hline Death & $1,507(7.7 \%)$ & $9,821(6.8 \%)$ & $<0.001$ \\
\hline Composite endpoint* & $7,125(36.3 \%)$ & $52,245(36.2 \%)$ & 0.668 \\
\hline \multicolumn{4}{|c|}{$\begin{array}{l}\text { Secondary outcome of PCP office visits and home-care services } \\
30 \text { days postdischarge }\end{array}$} \\
\hline $\begin{array}{l}\text { Community PCP visits, } \\
\text { mean } \pm \text { SD }\end{array}$ & $3.8 \pm 5.1$ & $3.1 \pm 4.6$ & $<0.001$ \\
\hline PCP visit, no. (\%) & $15,732(80.2 \%)$ & $108,266(75 \%)$ & $<0.001$ \\
\hline Home-care services, no. (\%) & $6,197(31.6 \%)$ & $38,745(26.8 \%)$ & $<0.001$ \\
\hline Composite endpoint, no. $(\%)^{\dagger}$ & $16,851(85.9 \%)$ & $117,290(81.2 \%)$ & $<0.001$ \\
\hline \multicolumn{4}{|l|}{90 days postdischarge } \\
\hline $\begin{array}{l}\text { Community PCP visits, } \\
\text { mean } \pm \text { SD }\end{array}$ & $8.2 \pm 10.1$ & $6.9 \pm 9.3$ & $<0.001$ \\
\hline PCP visit, no. (\%) & $18,112(92.3 \%)$ & $128,806(89.2 \%)$ & $<0.001$ \\
\hline Home-care services, no. (\%) & $7,256(37.0 \%)$ & $45,675(31.6 \%)$ & $<0.001$ \\
\hline Composite endpoint, no. $(\%)^{\dagger}$ & $18,504(94.3 \%)$ & $132,448(91.7 \%)$ & $<0.001$ \\
\hline
\end{tabular}

NOTE: Abbreviations: ED, emergency department; PCP, primary care physician; SD, standard deviation ${ }^{*}$ Composite endpoint $=$ readmission, ED visit, or death

${ }^{\dagger}$ Composite endpoint $=$ community PCP visit or home-care service. 
TABLE 3. Logistic Regression Modeling at 30 and 90 Days Post-Hospital Discharge Associated With the Impact of In-hospital Primary Care Physician Visit

\begin{tabular}{lcc}
\hline & Unadjusted & Adjusted \\
Variable & Odds Ratio & Odds Ratio \\
& $(95 \% \mathrm{Cl})$ & $(95 \% \mathrm{Cl})^{*}$ \\
\hline
\end{tabular}

Primary outcome of emergency department visit, hospital readmission, or death

30 days postdischarge

\begin{tabular}{|c|c|c|}
\hline Readmission & $1.16(1.10-1.22)$ & $1.03(0.97-1.08)$ \\
\hline ED visit & $0.88(0.84-0.92)$ & $0.88(0.84-0.92)$ \\
\hline Death & $1.15(1.06-1.24)$ & $0.88(0.81-0.96)$ \\
\hline Composite endpoint ${ }^{\dagger}$ & $1.01(0.98-1.05)$ & $0.92(0.89-0.96)$ \\
\hline \multicolumn{3}{|l|}{0 days postdischarge } \\
\hline Readmission & $1.15(1.10-1.20)$ & $1.00(0.96-1.04)$ \\
\hline ED visit & $0.89(0.86-0.92)$ & $0.89(0.86-0.93)$ \\
\hline Death & $1.14(1.08-1.21)$ & $0.87(0.82-0.93)$ \\
\hline Composite endpoint ${ }^{\dagger}$ & $1.01(0.98-1.04)$ & $0.90(0.87-0.92)$ \\
\hline \multicolumn{3}{|c|}{ ondary outcome of PCP office visits and home-care services } \\
\hline \multicolumn{3}{|c|}{0 days postdischarge } \\
\hline Community PCP visits & $1.35(1.31-1.41)$ & $1.21(1.16-1.25)$ \\
\hline Home-care services & $1.26(1.22-1.30)$ & $1.05(1.01-1.09)$ \\
\hline Composite endpoint ${ }^{\ddagger}$ & $1.41(1.34-1.47)$ & $1.16(1.11-1.21)$ \\
\hline \multicolumn{3}{|l|}{0 days postdischarge } \\
\hline Community PCP visits & $1.46(1.39-1.55)$ & $1.25(1.18-1.33)$ \\
\hline Home-care services & $1.27(1.23-1.31)$ & $1.05(1.01-1.08)$ \\
\hline Composite endpoint ${ }^{\ddagger}$ & $1.51(1.42-1.61)$ & $1.19(1.12-1.27)$ \\
\hline
\end{tabular}

NOTE: Abbreviations: $\mathrm{Cl}$, confidence interval; ED, emergency department; PCP, primary care physician.

*Adjusted for age, sex, being of low income, being from a rural region, and LACE score. LACE score is a validated measure predicting readmission risk and accounts for length of stay, acute admission, comorbid disease burden, and number of ED visits in the previous 6 months. ${ }^{20}$

${ }^{\dagger}$ Composite endpoint $=$ readmission, ED visit, or death

${ }^{\ddagger}$ Composite endpoint = community PCP visit or home-care service.

$P<0.001)$ and within 90 days of discharge $(14.2 \%$ vs $12.6 \%, P<0.001)$. Additionally, patients who were visited by their primary care physician while hospitalized were more likely to die within 30 days postdischarge than those who did not receive an in-hospital visit $(3.7 \%$ vs $3.2 \%, P<0.001)$ and similarly by 90 days postdischarge $(7.7 \%$ vs $6.8 \%, P<0.001)$ (Table 2$)$.

Patients who received an in-hospital visit were less likely to visit the emergency department at 30 days $(10.4 \%$ vs $11.6 \%, P<0.001)$ and at 90 days $(18.6 \%$ vs $20.5 \%, P<0.001)$ compared to patients who did not receive an in-hospital visit (Table 2 ).

The patients who received in-hospital visits by their primary care physician had a greater average number of primary care physician visits in the community at 30 days $(3.8$ vs $3.1, P<0.001)$ and 90 days $(8.2$ vs $6.9, P<0.001$ ) (Table 2). Additionally, a higher proportion of patients who received an in-hospital visit accessed home-care services at 30 days postdischarge $(31.6 \%$ vs $26.8 \%, P<0.001)$ and 90 days postdischarge $(37.0 \%$ vs $31.6 \%, P<0.001)$ (Table 2$)$.

\section{Primary Outcome}

There was no difference in proportion of patients who experienced the composite endpoint at 30 days (4227 [21.6\%] vs $30,848[21.4 \%], P>0.5)$ or 90 days
(7125 [36.3\%] vs 52,245 [36.2\%], P>0.6) for patients who received an in-hospital visit by their primary care physician compared to those who did not. The unadjusted model found no statistically significant difference between the 2 groups upon a primary care physician visit (odds ratio [OR]: 1.01; 95\% confidence interval [CI]: 0.98-1.04). However, once adjusting for differences in the groups for patient factors such as age, sex, location and health status, patients who received an in-hospital visit by their primary care physician had lower adjusted risk for the composite outcome at 30 days postdischarge (adjusted OR [aOR]: 0.92 ; 95\% CI: 0.89-0.96) and 90 days postdischarge (aOR: 0.90; 95\% CI: 0.87-0.92) (Table 3). Estimates for each individual component of the composite outcome revealed significantly lower risk for ED visit and death but similar risk for readmission at both 30 days and 90 days after hospital discharge for patients who received and in-hospital visit from their primary care physician and those who did not (Table 3).

\section{Secondary Outcome}

Patients who received an in-hospital visit by their primary care physician were more likely to experience the composite outcome of home-care services and community primary care physician visits at 30 postdischarge $(16,851 \quad[85.9 \%]$ vs $117,290 \quad$ [81.2\%], $P<0.001)$ and 90 days postdischarge $(18,504$ [94.3\%] vs $132,448[91.7 \%], P<0.001)$ compared to patients who did not receive an in-hospital visit (Table 3 ). Once accounting for patient variables such as age, sex, location, and health status, patients who received an in-hospital visit by their primary care physician had a higher adjusted risk for the composite outcome at 30 days postdischarge (aOR: 1.16; 95\% CI: 1.111.21 ) and 90 days postdischarge (aOR: 1.19; $95 \% \mathrm{CI}$ : 1.12-1.27) (Table 3).

\section{DISCUSSION}

Our population-based study of primary care physicians is among the first to examine outcomes of patients whose primary care physicians have a history of providing supportive visits to hospitalized patients. After controlling for risk differences in patients at hospital discharge, we found that a primary care physician visit to a patient in the hospital was associated with a lower adjusted risk for the composite outcome of death, emergent hospital readmission, or emergency department visit at 30 and 90 days postdischarge compared to hospitalized patients who did not receive a visit by their primary care physician. We found this to be driven by patients having a lower risk of emergency department visits and death, whereas there was a similar risk of hospital readmission. We also found that visited patients were more likely to access homecare services and have more primary care physician visits in the community following discharge. 
The unadjusted model differs substantially from the adjusted model. On the surface this is an apparent paradox where the unadjusted results suggest an association with potential harm or no difference with a supportive visit. Conversely, the adjusted model suggests a reduction in harms. The differences between the unadjusted and adjusted model is driven by changes in the point estimates for readmission and death rates at both 30 and 90 day postdischarge. Prior to adjustment, it appears as if a primary care physician visit is associated with a significant increase of death; however, upon adjustment, it is associated with a significant reduction in death. Interestingly, this is a different effect than that observed with the secondary analysis, where the adjusted analyses demonstrate a more modest (but still positive) effect of supportivecare visits. This observed change is likely due to differences in the patient groups. We can speculate that this may be an observed phenomenon of primary care physicians opting to visit their sicker patients, as perhaps it should be; however, further research is required to fully understand the real drivers of a supportive visit.

Our results are consistent with an earlier study that identified that a minority number of primary care physicians visit their hospitalized patients. ${ }^{24}$ As well, findings from a randomized controlled trial of 364 patients over 60 years old identified a limited impact of primary care physician visits on patient outcomes but noted enhanced access to community health services. ${ }^{12}$ Our work highlights the potential impact of primary care physician visits, which could, in theory, be leveraged and be an important role that primary care physicians can play in planning postdischarge care and improving the quality of care following hospitalization.

Our research study did not examine the impact of in-hospital primary care physician visits on patient satisfaction directly. However, it has been demonstrated that patients have a strong desire for their primary care physician to be involved in their hospital care and their preference is for direct contact, with face-to-face visits compared to telephone or other communication. ${ }^{25}$ This choice is important because dissatisfaction with services is associated with a loss of patient confidence in care quality and decreased adherence. ${ }^{26}$ Also, primary care physicians acknowledge that information exchange is lacking when their patients are discharged, and that improving this aspect of a patient's care transition is important. ${ }^{20}$ Research into discharge summaries as a tool to fill the communication gap has noted some success, yet there remains uncertainty regarding the type of information that should be included in a discharge summary, the time frame in which primary care physicians actually receive the summaries, and the accuracy of the information provided. ${ }^{20,27}$
Our use of population-based administrative data sources make the findings of our research generalizable to other similarly designed healthcare systems where a primary care physician may visit their hospitalized patients in a supportive-care role. We were interested in a complex patient-physician interaction with a number of potential confounding factors, and our use of a composite measure represents the broad outcomes from this contact. Our cohort methodology was designed to isolate the exposure of interest while maximizing uniformity between the 2 study groups on other characteristics. Additionally a number of potential confounding factors were considered in an effort to isolate the effect of the primary care physician inhospital visit such as age, comorbid disease, and risk of hospital readmission. ${ }^{12}$ The findings of our work support that of earlier research, but on a broader and more generalizable scale. ${ }^{12}$

There were notable differences between the intervention and control patient populations in the proportion of patients from rural regions who receive a supportive visit. This may be due to systemic differences between rural and nonrural regions with regard to access to care and ease of visit by primary care physicians. Alternatively, observed differences may be due to limitations of our study design in that some rural environments rely on primary care physicians to be involved in hospital care for the region. As such, they may actually be visiting their patients in a manner that was not captured as a supportive-care visit. This is an important area that should be pursued in the future.

We acknowledge there are limits to our research findings. First, the nature of administrative data introduces challenges to causal inferences. As such, we are careful to describe associations and not draw causative links as there may be additional variables influencing outcomes including the patient-physician relationship, the location of the hospital relative to the physician practice and/or home, the time of the primary care physician visit, primary care physician hospital privileges for supportive-care visits, and the number of other patients the primary care physician had in the same hospital at the same time. A second limitation is the use of the selected outcomes, which may not be direct measures of care quality. ${ }^{28}$ However, the selected outcomes have been shown to be good quality measures in other work relevant to health policy. ${ }^{8,20,21,29}$ Third, the use of a composite outcome may over- or underestimate an exposure's impact. ${ }^{19}$ Our composite outcome might have been dominated by some of its components. These observations may reflect the reality of primary care physicians visiting their sicker patients, or may be an attribute of the relatively short length of follow-up of the study design. Fourth, we cannot determine whether there were additional interventions in place that assisted the continuity of care for primary care physician 
visits. ${ }^{20,27}$ However, this research included a broad range of hospitals throughout a large province where there were no system-level quality interventions applied during this time. Fifth, our readmission rate may appear lower than other studies. However, our analysis is population based and not limited in focus to seniors. ${ }^{30}$ As well, our posthospitalization death rates are similar to others, and the readmission rates are comparable to other Canadian studies. ${ }^{31}$ Sixth, patients at higher risk for adverse outcomes may be identified as requiring more communication with their primary care physicians and we may not have fully captured this risk in our adjustment models, thereby underestimating the effect of exposure. ${ }^{27}$ Further, primary care physicians may be involved in major medical decisions such as transitions to palliative care. A supportive-care visit that facilitated these transitions and its ensuing outcomes may not have been included in our analysis. Seventh, our inherent assumption is that more care, such as posthospital primary care visits and home visits, denotes better care. This may not always be the case. ${ }^{32}$ Eighth, physicians may find it difficult to visit their patient in the hospital, even when asked. ${ }^{12}$ Finally, our findings are contingent on a system that supports primary care physicians being aware of their patients who become hospitalized. This is not only incumbent on any individual (eg, hospitalist) but a system where all providers work cohesively and seamlessly. On balance, however, these limitations do not overshadow our study's findings and conclusions.

Visits by primary care physicians to hospitalized patients are a longstanding tradition. The practice likely varies according to regional, patient, and individual physician characteristics. ${ }^{16-18,25}$ However, reimbursement codes for these services are present in a number of international healthcare systems' physician fee schedules with fairly modest remuneration amounts. The fairly nominal fee of less than $\$ 20$ CND for a supportive-care visit is similar to other systems and does not constitute a strong financial incentive to encourage this practice. The fee likely compensates the primary care physician for some of their time but comes with an opportunity cost to other aspects of their practice. Thus, results may differ in other environments or if the fee were higher, thereby incenting more primary care physicians to conduct visits. Indeed, the entire program for supportive hospital visits cost approximately $\$ 2.5$ million CND per year for the 13 million people in the province of Ontario. Future work in this area could address the overall value and cost-effectiveness of any potential fee changes. Still, it highlights the generalizability of our findings to other health systems and the ease in assessing the effect of the practice.

Overall, our findings underscore the importance and relevance for the practice of supportive-care visits in its association with patient outcomes and health services utilization, which may prove to be an important key factor to improve quality healthcare. Our results suggest that an in-hospital visit by a primary care physician may improve patient outcomes and increase subsequent support in the community. An inhospital supportive visit may be an additional method by which primary care physicians, and healthcare systems as a whole, strive to achieve the best care for patients.

\section{Acknowledgements}

Michael Manno, an analyst with the Institute of Clinical Evaluative Sciences (ICES) at the time of this study, assisted with the analyses.

Disclosures: This study was supported by the Institute for Clinical Evaluative Sciences (ICES), which is funded by an annual grant from the Ontario Ministry of Health and Long-Term Care (MOHLTC). The opinions, results, and conclusions reported in this article are those of the authors and are independent from the funding sources. No endorsement by the ICES or the Ontario MOHLTC is intended or should be inferred. No researcher or persons involved in this study had any declared or otherwise known conflicts of interest. Stacey Brener received funding from a Canadian Institutes of Health Research (CIHR) Master's award in the area of primary care; the Ontario Graduate Student in Science and Technology award, an award from the CIHR Women's College Hospital Interdisciplinary Capacity Enhancement Team, and team grant OTG88591 from the CIHR. Susan Bronskill is supported by a CIHR New Investigator Award in the Area of Aging. Chaim Bell is supported by a CIHR/Canadian Patient Safety Institute Chair in Patient Safety and Continuity of Care. These funding agencies had no role in the design and conduct of the study; collection, management, analysis, or interpretation of the data; or preparation, review, or approval of the manuscript. The corresponding author had full access to all of the data in the study and takes responsibility for the integrity of the data and the accuracy of the data analysis. The authors report no conflicts of interest.

\section{References}

1. van Walraven C, Mamdani M, Fang J, Austin PC. Continuity of care and patient outcomes after hospital discharge. J Gen Intern Med. 2004;19(6):624-631.

2. Brennan TA, Leape LL, Laird NM, et al. Incidence of adverse events and negligence in hospitalized patients: results of the Harvard Medical Practice Study I. 1991. Qual Saf Health Care. 2004;13(2):145-151; discussion 51-52.

3. Forster AJ, Murff HJ, Peterson JF, Gandhi TK, Bates DW. The incidence and severity of adverse events affecting patients after discharge from the hospital. Ann Intern Med. 2003;138(3):161-167.

4. The College of Family Physicians of Canada. Family physicians caring for hospital inpatients. Available at: http://www.cfpc.ca/uploadedFiles/Resources/Resource_Items/FPs20Inpt20Hosp20Care_En.pdf. Published October 2003. Accessed August 15, 2015.

5. Halm EA, Lee C, Chassin MR. Is volume related to outcome in health care?. A systematic review and methodologic critique of the literature. Ann Intern Med. 2002;137(6):511-520.

6. Lindenauer PK, Rothberg MB, Pekow PS, Kenwood C, Benjamin EM, Auerbach AD. Outcomes of care by hospitalists, general internists, and family physicians. N Engl J Med. 2007;357(25):2589-2600.

7. Stiell AP, Forster AJ, Stiell IG, van Walraven C. Maintaining continuity of care: a look at the quality of communication between Ontario emergency departments and community physicians. CJEM. 2005;7(3):155-161.

8. van Walraven C, Taljaard M, Etchells E, et al. The independent association of provider and information continuity on outcomes after hospital discharge: implications for hospitalists. J Hosp Med. 2010;5(7): 398-405.

9. Liss DT, Chubak J, Anderson ML, Saunders KW, Tuzzio L, Reid RJ. Patient-reported care coordination: associations with primary care continuity and specialty care use. Ann Fam Med. 2011;9(4):323-329.

10. Marchinko S, Clarke D. The Wellness Planner: empowerment, quality of life, and continuity of care in mental illness. Arch Psychiatr Nurs. 2011;25(4):284-293.

11. Tremblay D, Roberge D, Cazale L, et al. Evaluation of the impact of interdisciplinarity in cancer care. BMC Health Serv Res. 2011;11:144.

12. McInnes E, Mira M, Atkin N, Kennedy P, Cullen J. Can GP input into discharge planning result in better outcomes for the frail aged: results from a randomized controlled trial. Fam Pract. 1999;16(3):289-293.

13. Bell CM, Brener SS, Gunraj N, et al. Association of ICU or hospital admission with unintentional discontinuation of medications for chronic diseases. JAMA. 2011;306(8):840-847.

14. Bell CM, Bajcar J, Bierman AS, Li P, Mamdani MM, Urbach DR. Potentially unintended discontinuation of long-term medication use 
after elective surgical procedures. Arch Intern Med. 2006;166(22): 2525-2531.

15. Juurlink D, Preyra C, Croxford R, Chong A, Austin P, Tu J, Laupacis A. Canadian Institute for Health Information Discharge Abstract Database: A Validation Study. Toronto: Institute for Clinical Evaluative Sciences; 2006. Available at: http://www.ices.on.ca/Publications/ Atlases-and-Reports/2006/Canadian-Institute-for-Health-Information. Accessed August 15, 2015.

16. Chang CH, Stukel TA, Flood AB, Goodman DC. Primary care physician workforce and Medicare beneficiaries' health outcomes. JAMA. 2011;305(20):2096-2104.

17. Bynum JP, Bernal-Delgado E, Gottlieb D, Fisher E. Assigning ambulatory patients and their physicians to hospitals: a method for obtaining population-based provider performance measurements. Health Serv Res. 2007;42(1 pt 1):45-62.

18. Shah BR, Hux JE, Laupacis A, Zinman B, Cauch-Dudek K, Booth GL. Administrative data algorithms can describe ambulatory physician utilization. Health Serv Res. 2007;42(4):1783-1796.

19. Montori VM, Permanyer-Miralda G, Ferreira-Gonzalez I, et al. Validity of composite end points in clinical trials. BMJ. 2005;330(7491):594-596.

20. Kripalani S, LeFevre F, Phillips CO, Williams MV, Basaviah P, Baker DW. Deficits in communication and information transfer between hospital-based and primary care physicians: implications for patient safety and continuity of care. JAMA. 2007;297(8):831-841.

21. Lyons JS, O’Mahoney MT, Miller SI, Neme J, Kabat J, Miller F. Predicting readmission to the psychiatric hospital in a managed care environment: implications for quality indicators. Am J Psychiatry. 1997; 154(3):337-340.

22. Rumball-Smith J, Hider P. The validity of readmission rate as a marker of the quality of hospital care, and a recommendation for its definition. N Z Med J. 2009;122(1289):63-70.
23. van Walraven C, Dhalla IA, Bell C, et al. Derivation and validation of an index to predict early death or unplanned readmission after discharge from hospital to the community. CMAJ. 2010;182(6):551557.

24. van Walraven C, Taljaard M, Bell CM, et al. Information exchange among physicians caring for the same patient in the community. CMAJ. 2008;179(10):1013-1018.

25. Chan B. Supply of physicians' services in Ontario. Hosp Q. 1999; $3(2): 17$.

26. Bond M, Bowling A, Abery A, McClay M, Dickinson E. Evaluation of outreach clinics held by specialists in general practice in England. J Epidemiol Community Health. 2000;54(2):149-156.

27. Bell CM, Schnipper JL, Auerbach AD, et al. Association of communication between hospital-based physicians and primary care providers with patient outcomes. J Gen Intern Med. 2009;24(3): 381-386.

28. Krumholz HM, Lin Z, Keenan PS, et al. Relationship between hospital readmission and mortality rates for patients hospitalized with acute myocardial infarction, heart failure, or pneumonia. JAMA. 2013; 309(6):587-593.

29. Ashton CM, Wray NP. A conceptual framework for the study of early readmission as an indicator of quality of care. Soc Sci Med. 1996; 43(11):1533-1541.

30. Jencks SF, Williams MV, Coleman EA. Rehospitalizations among patients in the Medicare fee-for-service program. N Engl J Med. 2009; 360(14):1418-1428.

31. Dhalla IA, O'Brien T, Morra D, et al. Effect of a postdischarge virtual ward on readmission or death for high-risk patients: a randomized clinical trial. JAMA. 2014;312(13):1305-1312.

32. Grady D, Redberg RF. Less is more: how less health care can result in better health. Arch Intern Med. 2010;170(9):749-750. 